\title{
Desenvolvimento, distribuição e emprego ou o mercado de trabalho brasileiro à luz de Raúl Prebisch
}

\author{
Igor Zanoni Constant Carneiro Leão* \\ Newton Gracia da Silva**
}

\begin{abstract}
Resumo: O texto examina o problema do emprego na atualidade brasileira levando em consideração dados recentes do mercado do trabalho e a visão de um autor como Raúl Prebisch sobre emprego, distribuição de renda e desenvolvimento na América Latina. Esclarecemos que a heterogeneidade estrutural do mercado de trabalho latino-americano impede que o tema do "pleno emprego" seja analisado nos mesmos moldes do que ocorre nos EUA ou na Europa. Assim, há alguns segmentos ou ramos de atividade onde podem faltar trabalhadores especializados (em algumas regiões mais dinâmicas), ao passo que existe um imenso "exército industrial de reserva" na forma de desempregados, trabalhadores informais de baixa renda e até trabalhadores sem remuneração.
\end{abstract}

Palavras-chave: Emprego; Desenvolvimento; Raúl Prebisch.

Classificação JEL: E20; E24; O11.

\footnotetext{
* Doutor em Ciências Econômicas pela Universidade Estadual de Campinas (UNICAMP). Professor associado do Departamento de Economia da Universidade Federal do Paraná (UFPR). Endereço eletrônico: igor@ufpr.br.

** Graduando em Ciências Econômicas pela Universidade Federal do Paraná (UFPR). Bolsista do PET-Economia/ UFPR. Endereço eletrônico: newton.gracia@gmail.com. 


\section{Introdução}

A partir de 2003 a boa conjuntura internacional ${ }^{1}$, aliada à retomada dos gastos públicos e a lenta queda da taxa de juros real, fez com que a dramática questão do emprego no Brasil assumisse uma forma mais benigna, com queda significativa da taxa de desemprego aberto. É comum a preocupação de vários profissionais na área de mercado do trabalho com a escassez de trabalhadores qualificados para vagas que não podem ser preenchidas, mesmo numa situação caracterizada pelos entendidos em macroeconomia como de pleno emprego ou quase pleno emprego. As mudanças no mercado de trabalho foram significativas a ponto de se afirmar a existência de pleno emprego? O método a ser utilizado consiste na apresentação de alguns indicadores sobre o mercado de trabalho atual (Seção 2), analisados à luz do pensamento de Raúl Prebisch sobre o processo de desenvolvimento latino-americano (Seção 3). Por fim, algumas considerações são elaboradas a respeito do 'modelo brasileiro' de mercado de trabalho, num contexto em que o subdesenvolvimento é um dado estrutural desta economia.

Em primeiro lugar é preciso recordar que a preocupação com o pleno emprego no após-guerra nos países desenvolvidos conviveu com formas de produção caracterizadas pelo fordismo, por tecnologia estável, ascensão de uma nova classe média, pela construção de um avançado estágio de bem-estar social e pelo intervencionismo público na defesa do crescimento econômico. Isto pôde acontecer no contexto de acordos internacionais que soldaram a expansão das economias do centro e deram brecha para o desenvolvimento industrial de economias subdesenvolvidas como a Argentina, o Chile, Brasil e o México.

O objetivo do pleno emprego nas economias maduras teve, pois, uma série de condicionantes que já não existem, ou vêm sendo desconstruídos. Os trabalhadores de colarinho branco reduziram fortemente sua participação no emprego, levando a mudanças importantes na antiga e afortunada classe média. As novas tecnologias e novas formas de produção pós-fordistas criaram um grande contingente de desempregados que dificilmente voltará a ter lugar no mundo do trabalho. Finalmente, as crises sucessivas desde o final do século XX levaram a uma retomada de políticas conservadoras centradas na austeridade fiscal e monetária, no desmonte de partes significativas do Welfare State, tudo isso convergindo para novos problemas relativos ao desenvolvimento econômico e social.

No caso do Brasil, mesmo as elevadas taxas de crescimento até o final dos anos setenta e a construção de um incipiente estado de bem-estar, e de uma mimada classe média, são temas hoje em questão. Mesmo naquele período o mercado de trabalho sempre se caracterizou por aguda heterogeneidade e desigualdade, por um setor informal significativo e por salários de base medíocres.

1 Apesar do início da recuperação do produto em 2003, o ano foi marcado por uma tentativa de estabilização da taxa de câmbio, inflação, risco país (Embi+) e pela queda acentuada na taxa de juros (8,5 p.p. de resultado líquido), o que ainda caracteriza o período como pouco favorável ao crescimento. 


\section{Trabalho e desenvolvimento no Brasil atual}

Voltando ao debate contemporâneo sobre o Brasil, a ascensão da chamada classe $\mathrm{C}$ significa o predomínio no mercado de trabalho de trabalhadores com cerca de dois salários mínimos de renda mensal, o que sempre foi um piso baixo desse mercado. Inclusive porque o salário mínimo é muito reduzido e, por enquanto, a tentativa governamental de recuperação do salário mínimo caminha a passos lentos, se considerado o patamar vigente nos anos de 1960/70 como referência. Segundo o DIEESE, o salário mínimo deveria ser algo em torno de 2.400,00 reais, em janeiro deste ano, para que o trabalhador pudesse suprir suas necessidades básicas (alimentação, moradia, transporte, educação, vestuário, saúde, previdência e lazer). Ou seja, um salário 3,86 vezes superior ao mínimo que vigora seria necessário. Apesar de o rendimento médio real nas seis regiões metropolitanas que compõe a 'pesquisa mensal do emprego' ter alcançado o patamar dos $\mathrm{R} \$ 2.089,04$ em dezembro de 2011 e $\mathrm{R} \$ 1.699,70$ (em fevereiro de 2012), cerca de 50 milhões de brasileiros tem o salário mínimo como renda mensal. Se considerada a dinâmica do rendimento médio habitual real da população ocupada de fevereiro de 2003 a 2012, o último mês da série foi apenas $22 \%$ maior que o primeiro, totalizando um valor de $\mathrm{R} \$ 1.699,70$. Na 'Síntese dos Indicadores Sociais' do IBGE (2010), se observa que sob a perspectiva do rendimento familiar per capita, o intervalo entre mais de meio e dois salários mínimos compreendia 33,1\% das famílias brasileiras em 2009. Numa análise regional, o rendimento médio real habitual dos trabalhadores, na comparação entre fevereiro de 2011 e de 2012, apresentou aumento em Salvador (+18,6\%), Belo Horizonte (+7\%), Recife (+6,7\%), São Paulo (+5,4\%), Rio de Janeiro $(+0,4 \%)$ e declínio em Porto Alegre $(-2,4 \%)$. Deslocando a questão dos rendimentos para uma perspectiva ainda mais agregada, se observa que o aumento de $14,68 \%$ na massa de rendimento médio real habitual ${ }^{2}$ da população ocupada, por região metropolitana de 2009 a 2012 (comparação janeiro-janeiro), certamente tem como impulso o incremento de $27,72 \%$ do salário mínimo real no mesmo período. De fato, o aumento de 67,8\% do salário mínimo real de 2002-3 a 2011-3 (março) foi em grande parte responsável pelo aumento de $42,13 \%$ na massa de rendimento médio real no mesmo período. Em termos absolutos o indicador representa $\mathrm{R} \$$ 38.051 bilhões (janeiro de 2012) e, no período de doze meses entre fevereiro de 2011 e de 2012 , essa massa de rendimento cresceu $5,8 \%$.

A taxa de desemprego nas seis regiões pesquisadas pelo IBGE diminuiu dos 7,2\% (janeiro de 2010) para 5,5\% no início deste ano, mas não apresenta uma trajetória (de alta ou baixa) bem definida nesse horizonte de 24 meses. Por outro lado, se considerados os dez anos de 2002 a 2012 a trajetória é nitidamente de queda, saindo de uma taxa de desemprego (em percentual da PEA) acima dos $12 \%$ para os $5,8 \%$ em outubro de 2011 , conforme o gráfico a seguir:

\footnotetext{
2 O indicador é calculado através da soma ponderada (levando em consideração os pesos amostrais) de todos os rendimentos das pessoas ocupadas da amostra.
} 
Gráfico 1 - Taxa de desemprego: 2003.02 - 2012.02

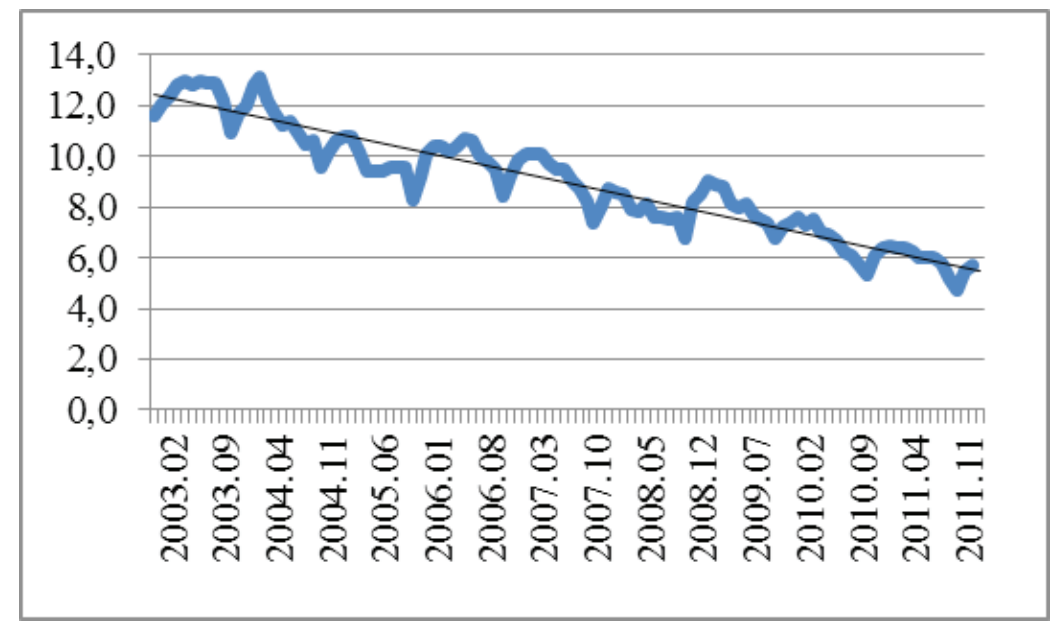

Fonte: Elaboração própria com base em IPEA (2012b).

É interessante destacar que nas regiões metropolitanas de Belo Horizonte e Porto Alegre o desemprego encerrou o ano passado abaixo dos cinco por cento, o que incentiva o debate a respeito do pleno emprego brasileiro. Para as mesmas seis regiões, a Tabela 1 abaixo demonstra a ocupação de maio (2010) a fevereiro (2012):

Tabela 1 - Nível de ocupação nas RMS pesquisadas

\begin{tabular}{rr|rr}
2010.5 & $\mathbf{5 3 \%}$ & 2011.4 & $\mathbf{5 3 , 4 \%}$ \\
2010.6 & $\mathbf{5 2 , 9 \%}$ & 2011.5 & $\mathbf{5 3 , 6 \%}$ \\
2010.7 & $\mathbf{5 3 , 2 \%}$ & 2011.6 & $\mathbf{5 3 , 5 \%}$ \\
2010.8 & $\mathbf{5 3 , 4 \%}$ & 2011.7 & $\mathbf{5 3 , 6 \%}$ \\
2010.9 & $\mathbf{5 3 , 7 \%}$ & 2011.8 & $\mathbf{5 3 , 9 \%}$ \\
2010.10 & $\mathbf{5 3 \%}$ & 2011.9 & $\mathbf{5 4 , 0 \%}$ \\
2010.11 & $\mathbf{5 4 \%}$ & 2011.10 & $\mathbf{5 4 , 0 \%}$ \\
2010.12 & $\mathbf{5 4 \%}$ & 2011.11 & $\mathbf{5 4 , 3 \%}$ \\
2011.1 & $53 \%$ & 2011.12 & $\mathbf{5 4 , 0 \%}$ \\
2011.2 & $53,2 \%$ & 2012.1 & $\mathbf{5 3 , 5 \%}$ \\
2011.3 & $53,3 \%$ & 2012.2 & $\mathbf{5 3 , 6 \%}$ \\
\hline
\end{tabular}

FonTE: Elaboração própria com base em IPEA (2012b).

Da população desocupada nas seis regiões metropolitanas investigadas pela Pesquisa Mensal do Emprego Fev-2012 (IBGE), 56,6\% é do sexo feminino, $34 \%$ têm idade na faixa etária entre 18 a 24 anos, quase $63 \%$ tem 11 ou mais anos de estudo e 51,6\% está procurando um emprego a 31 dias no mínimo, chegando até os seis meses no máximo. Por outro lado, na população ocupada $54,8 \%$ são do sexo masculino, apenas $13,5 \%$ têm idade na faixa de 18 a 24 anos, $62,3 \%$ têm 11 ou mais anos de estudo, $31,2 \%$ trabalham em empreendimentos com uma até cinco pessoas e $67,6 \%$ está há dois anos ou mais no emprego. De uma perspectiva setorial, ao se efetuar a combinação entre (a) percentual de empregados com carteira assinada em relação a (b) grupamento de atividade, se observa que: nos 'serviços prestados a empresa, aluguéis, atividades imobiliárias e intermediação financeira' $71,5 \%$ dos seus ocupados trabalham com carteira assinada e 10,5\% sem carteira; seguida pelo agrupamento da 'indústria extrativa, 
de transformação e distribuição (eletricidade, gás e água)' que tem 70,8\% dos seus ocupados trabalhando com carteira assinada e 9,6\% sem carteira; e em terceiro lugar, o agrupamento do 'comércio, reparação de veículos automotores e de objetos pessoais e domésticos e comércio a varejo de combustíveis' possui $53,7 \%$ dos seus ocupados trabalhando com carteira assinada, $12 \%$ sem carteira e $26 \%$ são trabalhadores por conta própria.

Ao se analisar o nível de ocupação segundo as características dos postos de trabalho, o 'Boletim Mercado de Trabalho - conjuntura e análise' (IPEA, 2012a) destaca que na comparação entre 2010 e 2011, os setores de intermediação financeira e construção tiveram desempenho favorável com aumento de $6,4 \%$ e $3,8 \%$ respectivamente. Por outro lado, os setores que apresentaram declínio foram os de serviços domésticos e outras atividades com -3,7\% e - -0,5\% respectivamente. A publicação ainda destaca que o setor industrial (conhecido pela relativa qualidade superior dos postos de trabalho) apresentou uma queda na população ocupada no $1^{\circ}$ trimestre de 2011 , seguida por um crescimento no segundo, enquanto no terceiro trimestre voltou a apresentar uma deterioração que se estendeu ao quarto trimestre, indicando perda de dinamismo no setor, pois o indicador se ajusta ao ocorrido nos níveis de produção industrial. No que diz respeito ao grau de informalidade, medido pelo contraste entre os resultados dos grupos de empregados com e sem carteira assinada, se verifica que o nível de informalidade médio da população ocupada em 2011 teve uma queda de 1,99 p. p. em relação a 2010 , ficando num patamar de $35 \%$.

As poucas evidências trazidas neste artigo demonstram que: (1) existe ociosidade do fator trabalho na economia brasileira; (2) quando o trabalhador se encontra desocupado, não há indícios de que seja uma opção voluntária por mais ócio e menos trabalho - à medida que a pesquisa revela que os desocupados buscam um emprego por dias e meses seguidos; (3) questões tradicionais como a recuperação do salário real, a relativa fragilidade dos jovens e os anos de estudo do trabalhador ainda se colocam em evidência como pontos de rigidez do mercado de trabalho brasileiro. Mesmo que se coloque o pleno emprego em termos mais imprecisos como 'um nível de desemprego cujos trabalhadores estão voluntariamente desempregados', ou 'nível de desemprego no qual todo aquele que deseja um emprego consegue facilmente', a situação brasileira se configura distinta desses conceitos. Isso para não tratar de um conceito tradicional de pleno emprego como 'uma curva de oferta agregada vertical (ou quase), na qual os incrementos na quantidade demandada resultariam numa elevação de preços'. Em outras palavras, um conceito em que o menor aumento da atividade econômica seria o suficiente para causar uma elevação nos níveis de preços.

Ao mesmo tempo, a política econômica atual acha-se dominada por preocupações de ordem monetária e fiscal, como resposta à crise internacional e como forma de assegurar baixa inflação. Entretanto, a ligação entre moeda, taxa de juros e nível de preços no regime de metas de inflação é resultado de uma regra, cujos coeficientes que determinam a importância relativa do desvio do produto e nível de preços são arbitrariamente definidos (Taylor, 1993, 
p. 202) ${ }^{3}$; o que permite (por exemplo) a realização de uma política consistente no tempo à custa da presunção de uma função social de perdas dos agentes racionais que valorizam a estabilidade de preços acima de qualquer objetivo macroeconômico. No Brasil, o debate sobre câmbio e juros tem dominado a agenda dos novo-desenvolvimentistas ${ }^{4}$, notando com justiça que o país insiste em uma taxa de câmbio irreal que tem levado à desindustrialização do parque produtivo e onerado as exportações. Mas a desindustrialização pode também ser relacionada ao nosso atraso tecnológico desde a última revolução industrial nos anos oitenta em diante.

Destarte, os dados expostos acima foram um exercício para delinear os contornos do mercado de trabalho atual (buscando os indícios de pleno emprego) em termos de seus preços (salários e rendimentos) e quantidades (emprego e ocupação), assim como o perfil da mercadoria (trabalho) quando ocupada ou não. Entretanto, colocar o mercado de trabalho nesses termos é irrelevante e pouco explicativo se considerado que sua origem e natureza são fenômenos que correspondem ao (sub) desenvolvimento econômico do país ao longo da história. Nesse sentido, a discussão sobre pleno emprego ou pressão sobre o mercado favorável aos trabalhadores torna-se risível.

\section{Raízes do subdesenvolvimento: o trabalho na América Latina}

Retomando um texto de Raúl Prebisch, de 1963, Dinâmica do Desenvolvimento Latino-Americano, vejamos brevemente como o autor sistematiza os problemas do crescimento, da distribuição e do emprego. A principal característica das economias latino-americanas seria uma insuficiência dinâmica entorpecendo o progresso técnico e seus rebatimentos sobre o desenvolvimento econômico e social. Assim, a estrutura social da região é marcada pela falta de mobilidade social, pelo privilégio na distribuição do emprego e da renda e pelo consequente ritmo débil de acumulação de capital, a não ser em formas exageradas do consumo nas camadas superiores da sociedade contrastando com a precária existência das massas populares.

A capacidade de imprimir maior ritmo de desenvolvimento é uma précondição para melhorar progressivamente a distribuição de renda. Uma condição aí para o autor é a compressão do consumo dos grupos de rendas elevadas, traduzindo-se em acréscimo contínuo do capital acumulado. Isto ocorre porque os problemas da acumulação de capital, bem como da distribuição de renda, colocam-se em termos muito diversos dos relativos à evolução capitalista dos países mais adiantados.

Outro ponto importante são as restrições à importação por parte dos Estados Unidos, influindo de forma diversa sobre as exportações latino-

\footnotetext{
3 No artigo, o autor afirma que "The policy rule in equation 1 has the general properties of the rules that have emerged from recent research, and the coefficients are round numbers that make for easy discussion".

4 Sobre a agenda política e os fundamentos econômicos desta ideologia novo-desenvolvimentista ver Sicsú et al. (2005) e Bresser-Pereira (2006).
} 
americanas, o mesmo ocorrendo com o então mercado comum europeu. Nesse contexto, o mercado comum latino-americano é um objetivo importante dependendo de um esforço convergente de grandes dimensões. O desenvolvimento fechado da região precisa ser superado através de cooperação internacional tanto no campo de intercâmbio quanto no campo do financiamento.

Por outro lado, havia estrangulamentos internos que limitavam ou impediam a força expansiva da acumulação de capital, como a insuficiente produção agrícola. Solucionar isto exige a brecha entre a renda média rural e urbana para o que é preciso que a agricultura possa reter o fruto de seu progresso técnico e ainda que o avanço tecnológico possa ser inserido numa política que não despeje sobre as cidades uma massa de população agora sem acesso à terra.

Para o autor, a tecnologia nos países desenvolvidos veio se introduzindo no processo produtivo à medida que se acumulava o capital necessário. Os países subdesenvolvidos, por sua vez, tendem a assimilar uma tecnologia já elaborada com incessantes inovações que nela ocorrem requerendo um elevado capital por pessoa, que os países do centro alcançaram dentro do seu regime histórico.

Estes dados fazem com que a política do desenvolvimento tenha que se basear em uma interpretação autêntica da realidade latino-americana. Em primeiro lugar é preciso conquistar novos graus na industrialização de nossos países. Além disso, é preciso redimensionar a inflação em termos teóricos para que não seja visto apenas como fruto da política monetária inflacionista, mas como fenômeno inerente à estrutura social. $\mathrm{O}$ planejamento deve se expandir como uma área central na teoria e nos problemas do desenvolvimento. É preciso também estar atento ao fato de a técnica produtiva contemporânea permitir também uma enorme concentração de poder econômico em mãos de poucos homens. O mesmo se observa nas técnicas de informação e difusão maciça de ideias. Isso coloca problemas sérios ao nosso desígnio de controlar consciente e deliberadamente as forças do desenvolvimento econômico e social.

A partir desse panorama teórico, vamos destacar os fatores estruturais internos do desenvolvimento latino-americano. O primeiro é a baixa taxa de crescimento da renda por habitante, sintoma da insuficiência dinâmica desse desenvolvimento. Uma proporção significativa do aumento da população ativa não se absorve de modo satisfatório no processo produtivo, permanecendo antes à margem do desenvolvimento econômico. Este fenômeno é mais visível na população que se desloca do campo para as cidades, onde encontram más condições de habitação e trabalho no conjunto de serviços pessoais de renda ínfima com períodos de desemprego total. Também nas cidades, além dos desocupados, existe um conjunto grande de mão de obra de salários muito inferiores originários de atividades urbanas que se modernizam.

As atividades que podem absorver essa população são a indústria, o comércio e o transporte, bem como os serviços pessoais qualificados e os serviços públicos. Destacam-se aí o papel da indústria e das atividades conexas como peças-chave na dinâmica da mão de obra. Para isso é preciso um ritmo mínimo de desenvolvimento com um ritmo adequado de acumulação de capital. A medida que aumenta a produtividade com o progresso técnico, tende a aumentar o coeficiente 
necessário no investimento para absorção da mão de obra. Caracteriza-se assim um quadro muito heterogêneo no setor serviços, demonstrando um excesso de população capaz de encontrar emprego.

A insuficiência dinâmica do sistema reside no desequilíbrio entre a produtividade e os investimentos. O capital requerido para absorver a mão de obra excedente provocada pela maior produtividade é superior à poupança que poderia viabilizar uma maior acumulação de capital, no pensamento de Prebisch. Do ponto de vista do empresário, eles adotam em seus investimentos as técnicas mais convenientes dados o custo do trabalho e do capital. No conjunto da economia essa lógica privada implica numa insuficiente absorção de mão de obra. Embora seja certo que não se possa retroceder na técnica produtiva, é possível optar por certo emprego de mão de obra, não como uma solução espontânea do mercado, mas como um objetivo da política econômica e do planejamento propriamente dito.

Outro problema importante reside em que o consumo nas camadas superiores da sociedade dirige-se mais frequentemente a produtos de indústrias intensivas em capital, enquanto que no resto da população ocorre o contrário. Fica claro, portanto, que a dinâmica do mercado de trabalho está relacionada intimamente com a distribuição da propriedade e da renda. Podemos pensar também no baixo crescimento da produção agrária latino-americana, que sugeria a urgência de políticas agrárias e agrícolas voltadas para o setor primário.

Fica claro também que é necessário obter um ritmo mínimo de desenvolvimento por habitante adequado; aliado a uma política firme de distribuição de renda a fim de contribuir para a correção do estrangulamento na balança comercial. A reforma agrária é desde logo essencial, mas apenas com ela não se resolveria o problema do baixo nível material de vida da população rural e das grandes massas no conjunto da economia. $\mathrm{O}$ aumento da produtividade agrícola com a mecanização da agricultura leva à eliminação da mão de obra, o que desperdiçaria o capital da comunidade. E isto implicava uma tarefa prévia de pesquisa tecnológica e de difusão dos seus resultados ou, em outros termos, uma atividade previsora do Estado.

Nesse estilo de argumentação a estrutura social e política da América Latina encontra-se na raiz da sua dinâmica econômica, da mesma forma como na origem da inflação latino-americana e do seu estrangulamento externo. Em particular, é no poder de certos grupos da sociedade para arbitrar sua renda que está a origem da inflação latino-americana, e não em fatores fiscais e monetários. Ao contrário, a estabilização monetária só é possível ligada a uma política de desenvolvimento econômico e equidade social. Podemos lembrar também na discussão a necessidade de estabelecer um progressivo equilíbrio entre a capacidade técnica e econômica da iniciativa latino-americana com a estrangeira, bem como a modernização da administração pública de modo a tornar eficiente a ação planejadora e o funcionamento das políticas públicas.

Façamos neste ponto alguns comentários sobre o texto de Raúl Prebisch aqui apresentado de forma breve e incompleta. Desde logo ele se ressente do tempo que medeia entre a sua publicação e o nosso início de século XXI. Podemos notar 
um viés teórico neoclássico, ou melhor, da síntese neoclássica (elaborada por John Hicks), quando coloca a poupança como condição para o investimento ${ }^{5}$. Todavia, há muito sabemos dessa utilização da teoria convencional pela primeira CEPAL adaptando-a às nossas necessidades e condições. Estas últimas ainda são as que o texto apreende: (i) a desigualdade, (ii) o êxodo rural, (iii) a heterogeneidade social, incluso o mercado de trabalho, (iv) a modernização do campo a expensas de qualquer cuidado profundo com custos humanos e ambientais. A seu modo e ao seu tempo, Raúl Prebisch, entre outros autores, soube pensar nossa falta de autonomia em conquistar a justiça e equidade junto com um desenvolvimento econômico mais bem estruturado e sustentado. Assim, ficam longe de um autor como este as especulações macroeconômicas como uma instância primeira na questão do desenvolvimento. Ao contrário, esta questão é pensada a partir da nossa herança cultural e colonial, modelando nossas instituições e os contornos do nosso contingente humano.

\section{Considerações finais}

Indicamos neste artigo que as preocupações com a industrialização e a modernidade característicos da CEPAL estão em baixa, e a discussão é tímida, vindo a reboque de uma interminável macroeconomia sobre câmbio e juros. É verdade que o governo tem procurado conter o afluxo de dólares, bem como baixar os juros. Mas o essencial é reconstruir um discurso sério que leve em conta a nossa história e estrutura social e econômica, recriando autonomia para nossos centros de decisão e construindo nexos de solidariedade que nos devolvam o conceito perdido de nação.

Um autor como Raúl Prebisch, mesmo com um instrumental macroeconômico que hoje consideraríamos limitado, soube ver questões de justiça social como a do emprego graças a um profundo conhecimento das estruturas econômicas e sociais da América Latina e de sua gênese histórica, reposta pelas decisões políticas que mantém, em um país como o Brasil, uma sociedade heterogênea e desigual, na qual um grande contingente humano se encontra em grande medida à margem da dinâmica econômica, vivendo de expedientes ou em grande pobreza. A dinâmica do mercado de trabalho talvez o atinja apenas incidentalmente e sua incorporação aos padrões de civilização material atingidos por outros grupos e classes sociais demanda políticas públicas específicas, não apenas o crescimento econômico, mas profunda redistribuição de propriedade, renda e poder político.

\footnotetext{
5 Se fosse possível traduzir o entendimento de Prebisch sobre o investimento em termos de uma equação, essa seria algo como $I=f(S)+\alpha$, na qual alfa representaria algumas condições institucionais para a inversão, tais como: preferência pela liquidez sob incerteza, taxa de juros, eficiência marginal do capital na economia e um ambiente público favorável.
} 


\section{Referências}

Bresser-Pereira, L. (2006). "O novo-desenvolvimentismo e a ortodoxia convencional". São Paulo em Perspectiva 20(1).

IBGE - Instituto Brasileiro de Geografia e Estatística. (2012). Pesquisa Mensal do Emprego. Brasília, fevereiro. URL [on-line]: http://www.ibge.gov. br/home/estatistica/indicadores/trabalhoerendimento/pme_nova/pme_ 201202pubCompleta.pdf. Acesso em: 15 de março de 2012.

IBGE - Instituto Brasileiro de Geografia e Estatística. (2012). Síntese dos Indicadores Sociais 2010. Brasília. URL[on-line]: http://www.ibge.gov.br/home/estatistica/ populacao/condicaodevida/indicadoresminimos/sinteseindicsociais2010/SIS_ 2010.pdf. Acesso em: 15 de março de 2012.

IPEA - Instituto de Pesquisa Econômica Aplicada. (2012). Boletim Mercado de Trabalho: conjuntura e análise. Brasília, n. 50, fev. URL [on-line]: http://www. ipea.gov.br/portal/images/stories/PDFs/mercadodetrabalho. Acesso em: 10 de abril de 2012 .

IPEA - Instituto de Pesquisa Econômica Aplicada. (2012). IPEA DATA. Brasília. URL [on-line]: www.ipeadata.gov.br. Acesso em: 20 de março de 2012.

Prebisch, R. Dinâmica do desenvolvimento latino-americano. (1964). Rio de Janeiro: Fundo de Cultura.

Sicsú, J; Paula, L; Michel, R. (2005). Novo-desenvolvimentismo: um projeto nacional de crescimento com equidade social. Rio de Janeiro: Manole: Fundação Konrad Adenauer.

Taylor, J. (1993). "Discretion versus policy rules in practice". Carnegie-Rochester Conference Series on Public Policy 39. 